\title{
Polyethylene recycling: waste policy scenario analysis for the EU-27
}

\begin{abstract}
This paper quantifies the main impacts that the adoption of the best recycling practices together with a reduction in the consumption of single-use plastic bags and the adoption of a kerbside collection system could have on the 27 Member States of the EU. The main consequences in terms of employment, waste management costs, emissions and energy use have been quantified for two scenarios of polyethylene (PE) waste production and recycling. That is to say, a "business as usual scenario", where the 2012 performances of PE waste production and recycling are extrapolated to 2020, is compared to a "best practice scenario", where the best available recycling practices are modelled together with the possible adoption of the amended Packaging and Packaging Waste Directive related to the consumption of single-use plastic bags and the implementation of a kerbside collection system. The main results show that socio-economic and environmental benefits can be generated across the EU by the implementation of the best practice scenario. In particular, estimations show a possible reduction of 4.4 million tonnes of non-recycled PE waste, together with a reduction of around €90 million in waste management costs in 2020 for the best practice scenario versus the business as usual scenario. An additional 35,622 jobs are also expected to be created. In environmental terms, the quantity of $\mathrm{CO}_{2}$ equivalent emissions could be reduced by around 1.46 million tonnes and the net energy requirements are expected to increase by 16.5 million GJ as a consequence of the reduction in the energy produced from waste. The main analysis provided in this paper, together with the data and the model presented, can be useful to identify the possible costs and benefits that the implementation of PE waste policies and Directives could generate for the EU.
\end{abstract}

Keywords: Polyethylene; Waste Policy; Recycling, EU Directive; Socio-Economic and Environmental Impacts 


\section{Introduction}

Waste management and its impacts on the economy and the environment are some of the most important challenges for countries experiencing increasing consumption rates (Cherubini et al., 2009; Laurent et al., 2014). According to data provided by the OECD (2013), the total municipal waste generation in OECD countries is expected to increase from 653 million tonnes per year in 2005 to 900 million tonnes per year in 2030. The largest variations are expected to take place in the South Asian countries and recent estimations quantified that China's solid waste generation could increase from 520 thousand tonnes per day in 2005 to 1.4 million tonnes per day in 2025 (Hoornweg et al., 2013). Within the European Union, large attention has always been paid to waste reduction and recycling and a large number of policies have been drawn up with that aim. Based on the idea that efficient waste management strategies can be useful to prevent or reduce adverse effects on the environment and human health, the EU approach to waste is based on the concept of the "waste hierarchy" which sets a specific priority order for the design of waste legislation. In decreasing order of priority, prevention, reuse, recycling, recovery and disposal are the main options for consideration in the shaping of waste policies. According to this approach, the $7^{\text {th }}$ Environmental Action Programme, the Resource Efficiency Roadmap and the Raw Materials Initiative specifically identify a set of strategies and priorities to improve waste management across EU. In addition to that, specific directives as he Packaging and Packaging Waste Directive (94/62/EC), the Waste Framework Directive (2008/98/EC) and the recent proposal for an amended Packaging and Packaging Waste Directive have also been designed to deal with waste management and recycling. According to data publicly available from Eurostat, the quantity of waste generated in the EU-27 decreased by around 115 million tonnes between 2004 and 2010. However, further improvements are expected to take place, particularly because the recent Sustainable Development Strategy considers waste prevention and recycling important pillars to achieve the Europe 2020 objectives for a more resourceefficient economy (Europe 2020 website). In addition, a recent review of waste policy and legislation has been specifically launched to harmonise the national measures on waste production and disposal. An example of that is provided by the amended Packaging and Packaging Waste Directive oriented at limiting the production of packaging waste and at promoting recycling, re-use and other forms of waste recovery. A set of requirements on the packaging weights and volumes have also been established together with the definition of labels to identify and classify the nature of the material used. The recycling targets for the 
different packages have been reviewed and harmonized across EU Member States. In order to identify the main impacts that the adoption of the amended Directive could generate on different economic sectors and geographical areas a specific Impact Assessment exercise has also been performed. That is because, according to different authors, the definition of specific policies for waste management and recycling need to be driven by analysis oriented to investigate the possible trade-off generated in socio-economic and environmental terms (Finnveden, 2007; Lilja, 2009; EEA, 2011, Song et al., 2013; Cucchiella, 2014). If from one side waste generation can potentially represent enormous costs in terms of pollution and resources depletion, on the other side an efficient management of waste can reduce the demand for primary materials and contribute to the energy supply (Massarutto et al., 2011; Simpson, 2012; Arafat et al., 2014; Menikpura, 2013). With this in mind, a large number of models and studies have recently been put forward to support decision-makers in the design of efficient waste management strategies (Herva and Roca, 2013a; Herva and Roca, 2013b; Cossu and Masi, 2013; Tan et al., 2014). These mainly deal with technological innovations, and cost-efficient solutions (Eriksson and Bisaillon, 2011; Tabasova et al., 2012; Lenzen et al., 2012; Al-Salem et al., 2014). Great attention has also been paid to investigating the indirect effects on socio-economic and environmental variables such as employment, emissions and resource depletion (Klan et al., 2003; Thomas and McDougall, 2005; Emery et al., 2007; Ekval et al., 2007; Cleary, 2009; EEA, 2011; Reich, 2013; Herva et al., 2014; Milutinovic, 2014). Until now, however, only a limited number of studies have been specifically oriented to consider, at the same time, the three impact categories reported above, or to investigate the socio-economic and environmental impacts generated by the management of a specific waste category (Ferrao et al., 2014 and Antonopoulos et al., 2014). In particular, to our knowledge, no previous studies quantify the socio-economic and environmental impacts generated by different scenarios of polyethylene (PE) waste management strategies in the EU as a whole and in individual Member States. Figure 1 suggests that polyethylene represents an interesting case study to investigate the possible effects of improvement in waste management and recycling, given that the average EU recycling, reuse and recovery rate of plastics is markedly lower than for other materials. In addition, since the recent proposal for an amended Packaging and Packaging Waste Directive specifically consider the reduction of plastic packaging and plastic bags as fundamental elements to reduce the impact on environment, an analysis of the possible socio-economic and environmental impacts could be useful to define policies and efficient implementation strategies. 
Figure 1. Recycling/Reuse/Recovery rate of different materials

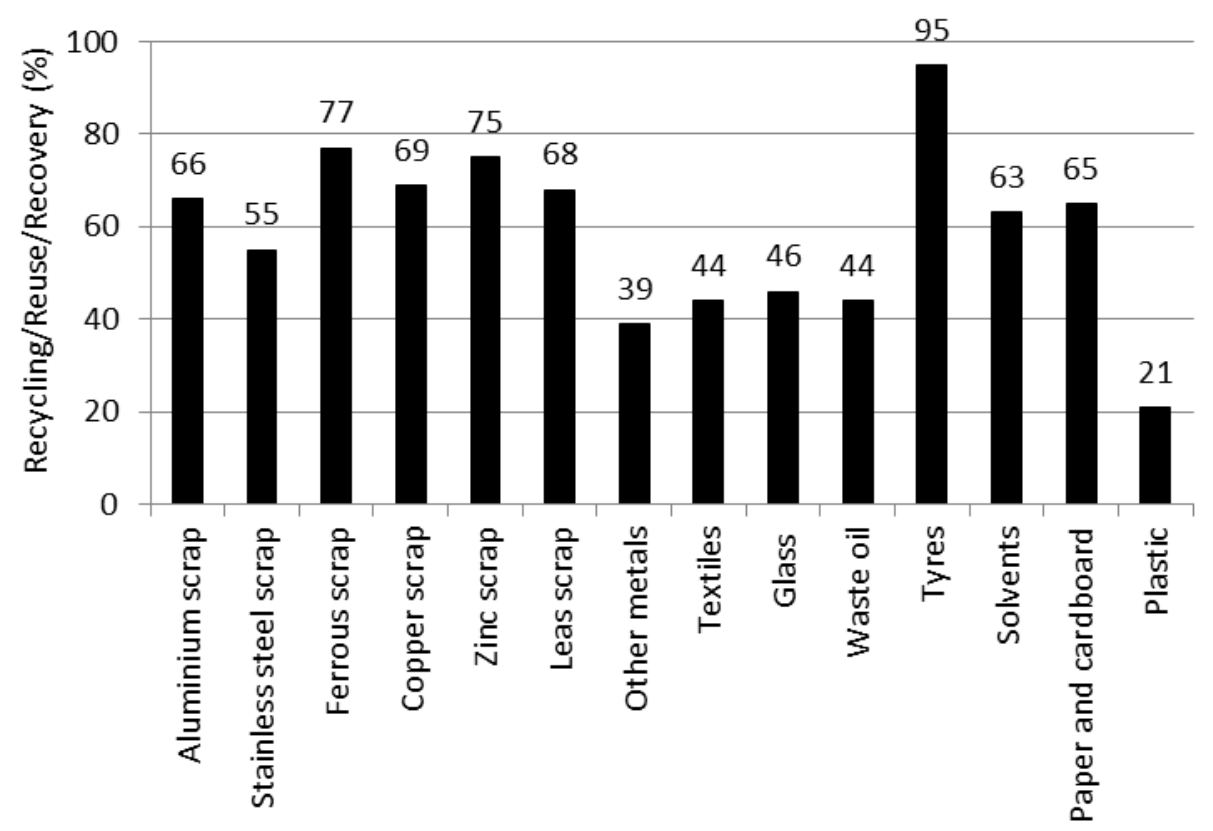

source: eurostat data (2007-2009)

Within this context, the present paper will specifically focus on the part of the amended Packaging and Packaging Waste Directive related to the reduction of the single-use carrier plastic bag. In particular, the impacts generated by the implementation of the scenario reported in the Option 3 of the Impact Assessment document prepared by the European Commission is considered together with the assumption of the implementation of the best available recycling practices and kerbside collection. In particular, the Impact Assessment document considers 4 different policy implementation options. The man objective is to assess the feasibility and impact of four different options for plastic carrier bags reduction. In the present paper Option 3 is considered. The main consequences in terms of employment, waste management costs, emissions and energy use are quantified at EU-27 level for the year 2020. A "business as usual scenario" is also modelled in this paper.

The paper is structured as follows. Section 2 summarizes the main data used to quantify the impacts generated on employment, waste management costs, emissions and energy. In Section 3 the methodology used to quantify the impacts on the EU as a whole and on the 
individual Member States is presented together with the scenarios analysed in the paper. Section 4 summarizes the main results and discusses the costs and benefits generated by the adoption of the best recycling practices together with the reduction in the use of the plastic bags and the implementation of a kerbside collection system. Section 5 identifies the main limitations and the possible future developments. Section 6 concludes.

\section{Data}

Eurostat data together with confidential data from Plastics Europe (2011) have been used to quantify the total amount of PE waste generated in 2012 across the different EU Member States. The same databases have also been used to disaggregate the total PE waste according to the PE categories reported in Table 1.

Table 1. PE waste disaggregation categories

\begin{tabular}{ll}
\hline Sector & PE waste categories \\
\hline Agriculture & Total agricultural PE waste \\
Industrial/commercial waste and household waste & Film (LDPE) \\
& Bags, sacks (HDPE/LDPE) \\
& Closures (HDPE/LDPE) \\
& Bottles (HDPE) \\
& Rigid containers (HDPE) \\
& Other \\
Construction & Total construction PE waste \\
\hline
\end{tabular}

The quantity of PE waste generated in 2012 (reported in Table S1 of the Supplementary material) has been used as a baseline for the scenario analysis performed in this paper. In particular, the following data have been used to quantify the socio-economic and environmental impacts generated in the EU-27 and in the different Member States by the waste production and recycling options considered in this study.

Costs for waste collection and waste treatment: Eurostat data, publicly available on the Eurostat website and National Statistics websites, together with data on capital costs provided by Eunomia (2002), Europe's Energy website, Eurostat Energy Statistics Database and WRAP (2008) have been used to quantify the collection costs (for kerbside and bring-based systems) and the waste treatment costs for the different EU Member States. The costs have been disaggregated into: 
- Capital costs, including site assessment, acquisition, capital expenditure and development, energy recovery equipment, restoration and aftercare, installation of machinery, vehicles and replacement of bins (Eunomia, 2002; WRAP, 2008);

- Operational costs, including labour costs, cost of energy and fuel (including taxes), machinery maintenance, insurance, landfill and incineration tax (Eurostat website);

- Energy generation revenues (Europe energy website; Eurostat Energy statistics Database).

Eurostat data have also been used to quantify the number of jobs associated to waste collection, treatment and recycling.

Recycling: Eurostat data on plastic recycling has been used to quantify the amount of PE recycled by the EU-27. The percentages of non-recycled PE waste allocated between the three disposal options considered in this paper (namely: landfill, incineration and mechanical biological treatment) have been quantified based on data collected from the European Environmental Agency website and previous EU reports (BIOS, 2012; ETC/SCP, 2012). The recycling costs have been quantified using the same data sources and the cost disaggregation used for the waste collection and the waste treatment costs (Eurostat website; Eunomia, 2002, WRAP, 2008). The revenue from the use of recycled material is included in the analysis, as well as the cost reduction generated by the substitution of virgin PE with recycled PE. The market prices for primary and secondary PE material have been obtained from the Plasticker website.

Environmental impacts: Two main environmental impacts have been considered in this paper, namely:

- Tons of $\mathrm{CO}_{2}$ equivalent

- Energy consumption

To estimate the emissions and the energy coefficients of PE manufacture from primary and recycled material the Plastic Europe's eco-profiles and the Ecoinvent v2.2 database have been used. Based on the framework of the UNEP-SETAC Life Cycle Initiative that account for the quantities of materials, energy and emissions used and generated along the entire polyethylene chain, the Plastic Europe's eco-profiles calculates the coefficients based on data provided by Europeans Plastic Manufacturers. In a similar way the Ecoinvent database is composed of data supplied by research centres and industry associations and quantify the 
environmental impacts by using the method of life cycle assessment (LCA) as standardised by the International Organisation for Standardisation (International Organization for Standardization (ISO) 2006a; International Organization for Standardization (ISO) 2006b) Since specific data for light plastic bags are not included in these databases, the mean value for low density polyethylene (LDPE) and high density polyethylene (HDPE) have been considered in this study.

The estimate the emissions and energy impacts related to PE waste management the coefficients provided by WRATE, the UK Environmental Agency's life cycle tool, have been used. The database contains information on a wide range of waste treatment facilities and the main environmental impacts are modelled by applying the life cycle assessment methodology used in the Ecoinvent database. For the case of polyethylene the main assumption considers a waste stream that is $25 \%$ dense plastic and $75 \%$ film plastic. The key assumptions used in the modelling of each of the treatment methods are summarised in Table S2 in the Supplementary material.

Since the emissions and the energy use coefficients are not disaggregated between the different Member States, the environmental impacts generated by PE production together with the environmental effects of the different non-recycled waste management options, have been calculated for the EU-27 as a whole. The specific coefficients used in this paper are reported in Tables 2 and 3.

Table 2. Emissions and energy coefficients of PE manufacture - per ton of material

\begin{tabular}{lcc}
\hline & $\begin{array}{c}\text { Emissions CO} \\
\left(\mathrm{kg} \mathrm{CO}_{2} \text { eq. }\right)\end{array}$ & $\begin{array}{c}\text { Energy content } \\
(\mathrm{MJ})\end{array}$ \\
\hline PE manufacture from primary material & 2,014 & 79,933 \\
PE manufacture from recycled content & 672 & 10,707 \\
\hline
\end{tabular}

source: plastic Europe's eco-profiles and ecoinvent v2.2 database

Table 3. Emissions and energy coefficients of PE waste management - per ton of waste

\begin{tabular}{llllll}
\hline & & Landfill & $\begin{array}{l}\text { Incineration } \\
\text { disposal }\end{array}$ & $\begin{array}{l}\text { Incineration } \\
\text { recovery }\end{array}$ & MBT \\
\hline & Unit & & & & \\
Emissions $\mathrm{CO}_{2}$ eq. & $\mathrm{kg} \mathrm{CO}$ eq. & 6.2 & 993 & 731 & 318 \\
Energy consumption & $\mathrm{MJ}$ & 120 & $-10,440$ & $-14,976$ & $-20,436$ \\
\hline source: wrate database & & & &
\end{tabular}

\section{Methodology}


To estimate the socio-economic and environmental impacts generated by different scenarios of waste production, disposal and recycling, a Polyethylene accounting model has been proposed in this paper based on the links between an EU-27 material flow model and an EU country-specific waste flow model. Figure 2 displays the PE model structure.

\section{Figure 2. Structure of the PE model}

In the PE model reported above, the quantity of PE waste generated by the different EU countries and disaggregated according to the PE product types reported in Table 1 is linked to polyethylene production in the EU-27. In this paper, the material recycled in one year is assumed to be completely incorporated into the production process of the following year, with a consequent reduction in the raw materials and energy demand. However, the model is designed to take into account the import and export of PE, as well as to account for stocks in society and production losses. Changes in gross domestic product, PE prices and consumption preferences can also be considered when investigating the impacts generated on PE consumption and PE waste generation. The EU country-specific waste flow model includes one worksheet for each country and accounts for the PE product type waste production together with the different disposal options. On this basis, the quantity of recycled materials, the waste management costs and the associated environmental impacts can be calculated for the EU as a whole and the 27 Member States individually.

With the help of this model and the data and assumptions reported in the previous section, the socio-economic costs generated by different scenarios of PE waste collection, waste disposal and recycling can be calculated for every one of the Member States. However, since the PE production process is modelled at EU-27 level and since the environmental coefficients are not available for every EU Member State, the total environmental impacts are only calculated at EU aggregate level.

As the main objective of this paper is to investigate the impacts generated by an improvement in the $\mathrm{PE}$ recycling rate and by the reduction in PE production linked to the drop in the use of plastic bags, as established in Option 3 of the Impact Assessment of the amended Packaging and Packaging Waste Directive, two scenarios have been considered in this paper:

Scenario A: This scenario represents the baseline, reflecting the 2012 situation of PE consumption, waste management and recycling. It is a "business as usual scenario" where the 
2012 performances of the different EU Member States are extrapolated to 2020, while taking into account an increase in polyethylene consumption linked to economic growth.

Scenario B: This scenario reflects full implementation of the best available recycling practices, plus full implementation of Option 3 defined in the Impact Assessment document prepared by the European Commission for the amended Packaging and Packaging Waste Directive. In particular, this scenario assumes:

- Full implementation of the best available recycling practice. It starts from the hypothesis that by 2020 all Member States will have a PE recycling rate of $56 \%$, which corresponds to the recycling performance of Germany in 2010. The recycling rate for every country is assumed to increase with a constant trend between 2013 and 2020. The non-recycled waste will be allocated to landfill, incineration and mechanical biological treatment based on the same 2012 allocation.

- Implementation of the Option 3 of the Impact Assessment of the amended Packaging and Packaging Waste Directive: a steady decrease in single-use carrier bags is assumed to take place in all Member States until an $80 \%$ reduction is reached in 2020 .

Since Member States will be free to determine the instruments used to meet this target, such as pricing measures or market restrictions, the economic impacts generated by Option 3 have not been included in the Impact Assessment prepared by the European Commission and will not be considered in this study.

- A kerbside system for collecting PE waste from households and businesses is also assumed to be gradually introduced as established in the recent review of the waste policies and legislation: by 2020 all EU-27 countries are expected to operate a $90 \%$ kerbside collection system. Specialist items, such as agricultural plastic, are assumed to be collected via a bring-based system.

In both scenarios, PE consumption is anticipated to increase across the EU as a consequence of economic growth. According to data provided by Eurostat (2014), the gross domestic product has increased by around 1\% in 2013 and for the time period between 2014 and 2020, we assume a gross domestic product variation of $+2 \%$ a year. As such, a $15 \%$ increase in the total amount of PE waste generated, will take place between 2012 and 2020 as a consequence of consumption increase. 
By using the model and the data reported above, the main socio-economic impacts generated by scenarios A and B in the different EU Member States have been calculated for the period 2012-2020. The environmental impacts have been estimated at EU level.

\section{Results and discussion}

The main results generated by using the PE model developed in this study, according to the two scenarios described above, highlight that the full implementation of the best available recycling practices, together with the reduction in the consumption of single-use plastic bags and the adoption of a kerbside collection system, generate a cost reduction both in economic and environmental terms. The specific impacts generated by scenarios $\mathrm{A}$ and $\mathrm{B}$ have been disaggregated as follows:

Scenario A - Baseline scenario. The following costs are expected to be generated in 2020 across the EU:

- At EU aggregate level, the total cost of PE waste management is expected to increase by $22.4 \%$, as a consequence of the additional quantity of PE waste generated across the EU (Table S3). According to data reported in Table 4, the total costs for PE waste management are expected to grow from $€ 1,674$ million in 2012 to $€ 2,048$ million in 2020.

- An additional 4,106 jobs in the PE waste management sector will be created to deal with the increased quantity of PE waste generated in the EU.

- According to data reported in Tables 5 and 6, an emissions increase of 1,276 thousand tonnes of $\mathrm{CO}_{2}$ equivalent, associated with managing the additional PE waste, plus 2,699 thousand tonnes of $\mathrm{CO}_{2}$ equivalent generated by $\mathrm{PE}$ manufacturing is expected to take place in 2020, compared to the levels of 2012. The total increase in emissions is thus quantified as 3,975 thousand tonnes of $\mathrm{CO}_{2}$ equivalent.

- An increase of 48 million GJ of energy produced from PE waste will be generated in 2020 according to data reported in Table 5.

The increasing quantity of PE waste generated across the EU-27, as a consequence of the gross domestic product increase, is the main factor influencing the changes in the socioeconomic and environmental impacts that are expected to take place between 2012 and 2020, in this scenario. 
Scenario B - Full implementation of the best available recycling practices plus reduction in the use of plastic bags and the implementation of a kerbside collection system. The following costs are expected to be generated across the EU-27:

- At EU-27 aggregate level, the total cost of PE waste management is expected to increase by $17 \%$ (Table S3), as a consequence of implementation of the kerbside system, and as a consequence of the PE waste generation increase generated by gross domestic product variation. According to data reported in Table 4, the total costs are expected to increase from $€ 1,634$ million in 2012 to $€ 1,958$ million in 2020 .

- An additional 39,728 jobs in the PE waste management sector are expected to be created between 2012 and 2020 to deal with the kerbside collection system and the increased recycling rate.

- According to data reported in Tables 5 and 6, an emissions reduction of 481 thousand tonnes of $\mathrm{CO}_{2}$ equivalent is expected to take place in 2020, compared to 2012. This reduction will be mainly attributed to the reduction in non-recycled PE waste generated by the drop in the consumption of plastic bags. However, since an additional 1.96 million tonnes of $\mathrm{CO}_{2}$ equivalent emissions are expected to be generated by increased PE manufacturing in 2020 related to the economic growth trend, this leads to a net overall increase in $\mathrm{CO}_{2}$ emissions of 1.48 million tonnes, compared to the 2012 level.

- As reported in Table 6, an additional 63.6 million GJ will be needed in 2020 for PE manufacturing. A reduction of nearly 6 million GJ of energy produced from incineration of PE waste is expected to take place in 2020, compared to the 2012 figure.

Comparisons between Scenario A and Scenario B - The net changes generated by the implementation of the best available practices compared to the values generated under the baseline conditions have been quantified as:

- A reduction of 4.4 million tonnes of non-recycled PE waste, disaggregated into:

$\circ$ A reduction of 3.2 million tonnes of PE waste generated by the reduction in the use of plastic bags.

- The collection of an additional 1.2 million tonnes of PE recycling material related to the increase in the recycling rate.

- According to data reported in Table 4, the reduction in the total costs of PE waste management has been quantified at about $€ 89.9$ million. Since the cost in the baseline 
scenario of managing PE waste in 2020 is around $€ 2,048$ million and the cost in the best practice scenario is $€ 1,958$ million, this represents a $4.39 \%$ costs decrease.

- The number of jobs associated with PE waste management increases significantly, as an additional 35,622 jobs are estimated to be created on top of the 27,357 jobs that would be required under the baseline conditions.

- Based on data reported in Tables 5 and 6, an emissions reduction of 1.76 million tonnes of $\mathrm{CO}_{2}$ equivalent would be generated by the reduction in the treatment of $\mathrm{PE}$ waste management. Further savings of 737 thousand tonnes of $\mathrm{CO}_{2}$ equivalent are expected from the use of the additionally recovered PE to manufacture new PE. However, the change in the waste collection system will result in the consumption of an additional 394 million litres of diesel, which, in turn, will result in 1.02 million additional tonnes of $\mathrm{CO}_{2}$ equivalent. Hence, the net emissions reduction is estimated at around 1.46 million tonnes of $\mathrm{CO}_{2}$ equivalent.

- The increased recycling rate and the consequent reduction in the amount of primary $\mathrm{PE}$ that is manufactured results in a reduced energy requirement of 37.5 million GJ. However, the reduction in the amount of PE waste sent for incineration will result in a reduction in the associated energy generation of 54 million GJ. The net variation, calculated as the difference between the energy produced from waste and the energy required for PE production and PE waste management, accounts for 16.5 million GJ.

The reduction in the use of plastic bags, together with an increase in the recycling rate and a kerbside collection system will result in a reduction of waste management costs at EU-27 aggregated level. However, according to data reported in Table S3 of the Supplementary material, in some countries, such as the Czech Republic, Greece, Spain, Finland, Hungary, Ireland, Italy and Slovenia, the PE management cost is expected to increase. The main reason is that these countries would need to implement significant structural changes in order to implement the three conditions established in Scenario B. In particular, they have to: (i) implement a kerbside sort system, which is more expensive than the bring-based system currently in use in these countries; (ii) increase the recycling infrastructure and performance; (iii) increase the number of people employed in the PE waste management sector. As reported in Table S4 of the Supplementary material, these countries are also some of the countries with the largest rate of employment increase.

Table 4. EU27 - PE management costs (million $€$ ) and employment in 2012 and 2020

2012 Scenario Change Scenario Change Net




\begin{tabular}{|c|c|c|c|c|c|c|}
\hline & & $\begin{array}{c}A \\
2020\end{array}$ & $\begin{array}{c}\text { 2012-2020 } \\
\text { Scenario } \\
\text { A }\end{array}$ & $\begin{array}{c}B \\
2020\end{array}$ & $\begin{array}{c}2012-2020 \\
\text { Scenario } \\
\text { B }\end{array}$ & $\begin{array}{c}\text { impact of } \\
\text { best } \\
\text { practice } \\
\text { (B-A) } \\
2020\end{array}$ \\
\hline PE costs & $1,673.7$ & $2,048.2$ & 374.5 & $1,958.4$ & 284.7 & -89.8 \\
\hline PE employment & 23,251 & 27,357 & 4,106 & 62,979 & 39,728 & 35,622 \\
\hline
\end{tabular}

Table 5. Environmental impacts of PE waste treatment in 2012 and 2020

\begin{tabular}{|c|c|c|c|c|c|c|}
\hline & 2012 & $\begin{array}{c}\text { Scenario } \\
\text { A } \\
\mathbf{2 0 2 0}\end{array}$ & $\begin{array}{c}\text { Scenario } \\
\text { A } \\
\text { Change } \\
\text { 2012-2020 }\end{array}$ & $\begin{array}{c}\text { Scenario } \\
\text { B } \\
2020\end{array}$ & $\begin{array}{c}\text { Scenario } \\
\text { B } \\
\text { Change } \\
\text { 2012-2020 } \\
\end{array}$ & $\begin{array}{c}\text { Net impact } \\
\text { of best } \\
\text { practice } \\
\text { (B-A) } \\
\end{array}$ \\
\hline $\begin{array}{l}\text { Emissions } \\
\text { (thousand } t \\
\text { CO2 eq.) }\end{array}$ & 2,054 & 3,330 & 1,276 & 1,573 & -481 & $-1,757$ \\
\hline $\begin{array}{l}\text { Energy } \\
\text { consumption } \\
\text { (thousand } \\
\text { GJ) }\end{array}$ & $-54,715$ & $-102,935$ & $-48,220$ & $-48,792$ & 5,923 & 54,143 \\
\hline
\end{tabular}

Table 6. Environmental impacts of PE manufacture in 2012 and in 2020

\begin{tabular}{lccc}
\hline & $\mathbf{2 0 1 2}$ & $\mathbf{2 0 2 0}$ & $\mathbf{2 0 2 0 - 2 0 1 2}$ \\
\hline $\begin{array}{l}\text { Emissions } \\
\text { (thousand t CO2 eq.) }\end{array}$ & & \\
$\begin{array}{l}\text { Scenario A } \\
\text { Scenario B }\end{array}$ & 18,764 & 21,462 & 2,698 \\
Net change 2020 (B-A) & 18,764 & 20,725 & 1,961 \\
\hline Energy consumption & & -737 \\
(thousand GJ) & & & \\
Scenario A & & & \\
Scenario B & 710,557 & 811,669 & 101,112 \\
Net change 2020 (B-A) & 710,557 & 774,151 & 63,594 \\
\hline
\end{tabular}

\section{Limitations and future developments}

A number of assumptions were made in this paper to deal with the limited availability of data. In particular:

- Waste generation: Since Eurostat data on waste generation are only available at aggregated level some confidential data provided by Plastics Europe together with data included in Plastics Europe (2011) have been used to disaggregate the total 
quantity of PE waste provided by Eurostat according to the classification reported in Table 1.

- Implementation of best practice recycling rate and kerbside collection: the recycling rate for every country is assumed to increase with a constant trend between 2013 and 2020. However, it must be kept in mind that setting such a timeframe may not always be realistic. Due to discrepancies in local markets, facilities, investment capacities, or human resources some Member States may be able to meet the targets faster than others.

- Cost of waste collection, treatment, recycling and revenue from energy and recycled material: the costs have been inflated up to 2020 prices. According to the inflation target of the EU, a yearly $2 \%$ price increase has been considered in this paper. However, based on specific technological development hypotheses, it might be possible to include different trends on prices and revenues.

- The number of jobs provided by Eurostat is available for the waste management sectors at aggregated level. The numbers of jobs related to PE management have been calculated as a proportion of the PE waste over the total waste generated.

- Environmental coefficients: Since data on energy and $\mathrm{CO}_{2}$ equivalent emissions are not available for every single Member State, the Ecoinvent data have been used at EU aggregated level. These coefficients are applied for the time period 2012-2020. However, based on technological developments and differences between Member States, improvements in energy efficiency and emissions reduction might be included in the model.

- The gross domestic product variation is assumed to be $2 \%$ a year between 2013 and 2020. However, different rates can be used to identify the impacts that economic growth/degrowth could generate on PE consumption and waste.

In spite of these assumptions, the model presented in this paper has been made using the most reliable information presently available at EU and Member State level. Therefore, the results presented could be useful to identify the socio-economic and environmental impacts that different PE waste management and recycling policies could have at EU and Member State level. Some developments are possible and desirable. First of all, the main limitations reported above could be overcome by the availability of updated and disaggregated data. In particular, specific environmental coefficients for the different Member States and for different production and waste management technologies would be needed to provide better 
estimations of the total environmental impacts generated at EU and Member State level. Secondly, according to the structure of the model, imports and exports of PE and recycled material, together with stocks in societies and production losses, could be added to model the extra-EU impacts generated by PE recycling and waste reduction policies. In addition, the impacts and effectiveness of market-based incentives or taxation for recycling and waste reduction could be introduced into the model.

\section{Conclusion}

This paper quantified the socio-economic and environmental impacts generated by different scenarios for polyethylene (PE) waste production and polyethylene waste management and recycling in the EU as a whole and the 27 individual Member States. Using data provided by Eurostat, National Statistics, Plastics Europe, Europe's Energy, the Ecoinvent database and previous EU reports, a PE model has been specifically designed to account for PE production and PE waste management. In this paper two main scenarios have been considered. The first one is a "business as usual scenario" where the 2012 performances on PE waste production and PE waste management and recycling are extrapolated to 2020. The second one considers the full implementation of the best available recycling practices together with the reduction in the consumption of single-use plastic bags and the adoption of a kerbside collection system. The main results show that significant socio-economic and environmental benefits could be generated across the EU by the implementation of the best practices scenario. In particular:

- A reduction of 4.4 million tonnes of non-recycled PE waste, together with a reduction of $€ 90$ million in waste management costs, is expected to take place in 2020.

- As a consequence, the quantity of $\mathrm{CO}_{2}$ equivalent emissions should reduce by around 1.46 million tonnes. However, the total energy requirement should increase by 17 million GJ, calculated as the difference between the reduction of the energy produced from waste and the energy required for PE production and for PE waste management.

- The number of waste management-associated jobs is expected to increase in both scenarios. However, in the best practice scenario the number of jobs created has been estimated to be 35,600 higher than in the business as usual scenario.

According to the results provided in this paper, the adoption of the best available recycling practices, together with the reduction of single-use plastic bags and the implementation of a kerbside collection system would be able to generate socio-economic and environmental 
benefits across the EU, with some differences between Member States. However, considering that the data used in this paper have not been able to take into account technological developments or faster adoption paths, the benefits expected in reality could be greater than the results presented in this paper. The scenario modelled in the present version of the paper is a middle ground scenario where improvement on recycling rate and PE consumption are expected to take place in line with the recent revision of the waste legislations and directives. More ambitious scenarios could also be modelled and the impacts on socio-economic and environmental variables could be estimated to identify the consequences that more challenging targets could generate at EU or at Member State level. In both cases, however, a careful analysis of the short and long term benefits and costs should be taken into account together with an objective evaluation of the feasibility of any kind of requirements.

Additional data and some model development oriented to include more socio-economic and environmental variables could be added to the modelling framework presented in this study. In general terms, however, the analysis presented is a good starting point to support the development and analysis of new EU policy proposals oriented towards recycling and PE waste reduction.

The accounting model developed in this study provides several advantages and generates new options for the evaluation of policy measures and the design of new policy proposals. By focussing on a single component of waste, rather than on the entirety of a mixed municipal or industrial waste stream, this study was able to model socio-economic impacts related to changes in the management of a specific material encountered in these waste streams. Such component-specific analysis can help in identifying how overall environmental benefits from (new) waste policy measures can be attributed to the different building blocks of the waste flow. This type of analysis could also assist in assessing the impacts of targeted policy options, such as measures to reduce single-use plastic bags, by highlighting the benefits and challenges of these material-specific measures. As such, it may help in complementing or rethinking existing waste policy measures that may have limited effects for certain elements of the waste flow. For example, low-density materials such as plastics may receive low priority in policy tools aimed at improving recycling rates on a weight basis, but could benefit from measures based on overall emission savings in waste management.

\section{Disclaimer}


The views expressed are purely those of the authors and may not in any circumstances be regarded as stating an official position of the European Commission. 


\section{References}

Al-Salem, S.M., Evangelisti, S., Lettieri, P., 2014. Life cycle assessment of alternative technologies for municipal solid waste and plastic solid waste management in the Greater London area. Chem. Eng. J. 224, 391-402.

Antonopoulos, E.S., Perkoulidis, G., Logothetis, D., Karkanias, C., 2014. Ranking municipal solid waste treatment alternatives considering sustainability criteria using the analytical hierarchical process tool. Resour. Conserv. Recy. 86, 149-159.

Arafat, H.A., Jijakli, K., Ahsan, A., 2014. Environmental performance and energy recovery potential of five processes for municipal solid waste treatment. J. Clean. Prod. (in press).

BIOS IS/Eudomia/IEEP/Ecologic, 2012. Use of Economic Instruments and Waste Management Performance. Final Report for DG Environment, April 2012.

Cherubini, G., Bargigli, S., Ulgiati, S., 2009. Life cycle assessment (LCA) of waste management strategies: Landfilling, sorting plant and incineration. Energy J. 34, 2116-2123.

Cleary, J., 2009. LCA of municipal solid waste management systems: a comparative analysis of selected peer-reviewed literature. Environ. Int. 35, 1256-1266.

Cossu, R., Masi, S., 2013. Re-thinking incentives and penalties: Economic aspects of waste management in Italy. Waste Manage. 33(1), 2541-2547.

Cucchiella, F., D’Adamo, I., Gastaldi, M., 2014. Sustainable management of waste-to-energy facilities. Renew. Sust. Energ Rev. 33, 719-728.

Ecoinvent v.2.2 database: http://www.ecoinvent.org/Accessed on 10/04/2015

EEA. 2011. Earnings, jobs and innovation: the role of recycling in a green economy. EEA Report No 8/2011. Copenhagen, Denmark: European Environmental Agency; 2011, ISSN 1725-9177.

Ekvall, T., Assefa, G., Eriksson, O., Finnveden G., 2007. What life-cycle assessment does and does not do in assessments of waste management. Waste Manage. 27, 989-996.

Emery, A., Davies, A., Griffiths, A., Williams, K., 2007. Environmental and economic modelling: a case study of municipal solid waste management scenarios in Wales. Resour. Conserv. Recy. 49, 244-263.

Environmental Action Programme: http://ec.europa.eu/environment/newprg/

Eriksson, O., Bisaillon, M., 2011. Multiple system modelling of waste management. Waste Manage. $31,2620-2630$.

ETC/SCP, 2012. Waste Implementation Project: Ex-post MSW Analysis - Reports produced for the European Environmental Agency.

Eudomia, 2009. Assessments of the options to improve the management of biowaste in the European Union - Report produced for the European Commission, DG Environment, November 2009. 
Eunomia, 2002. Costs for Municipal Waste Management in the EU. Final Report and Annexes to DG Environment, European Commission.

EUROPE 2020 website: http://ec.europa.eu/europe2020/index_en.htm. Accessed on 10/04/2015

Europe's Energy website: http://www.energy.eu/\#fueltaxes Accessed on 10/04/2015

European Environmental Agency website: www.eea.europa.eu

Eurostat Energy Statistics Database. Available http://epp.eurostat.ec.europa.eu/portal/page/portal/energy/data/database Accessed on 10/04/2015

Eurostat, 2014: http://epp.eurostat.ec.europa.eu/cache/ITY_PUBLIC/2-14022014-AP/EN/214022014-AP-EN.PDF

Ferrao, P., Ribeiro, P., Rodrigues, J., Marques, A., Preto, M., Amaral, M., Domingos, T., Lopes, A., Costa, I., 2014. Environmental, economic and social costs and benefits of a packaging waste management system: A Portuguese case study. Resour. Conserv. Recy. 85, 67-78.

Finnveden, G., Bjorklund, A., Moberg, A., Ekvall, T., 2007. Environmental and economic assessment methods for waste management decision-support: possibilities and limitations. Waste Manage. Res. 25, 263-269.

Herva, M., Neto, B., Roca, E., 2014. Environmental assessment of the integrated municipal solid waste management system in Porto (Portugal). J. Clean. Prod. 70, 183-193.

Herva, M., Roca, E., 2013a. Ranking municipal solid waste treatment alternatives based on ecological footprint and multi-criteria analysis. Ecol. Indic. 25, 77-84.

Herva, M., Roca, E., 2013b. Review of combined approaches and multi-criteria analysis for corporate environmental evaluation. J. Clean. Prod. 39, 355-371.

Hoornweg, D., Bhada-Tata, P., Kennedy, C., 2013. Environment: waste production must peak this century. Nature 502, 615-617.

Klang, A., Vikman, P., Brattebo, H., 2003. Sustainable management of demolition waste - an integrated model for the evaluation of environmental, economic and social aspects. Resour. Conserv. Recy. 38, 317-334.

Impact Assessment Document is available at: http://eur-lex.europa.eu/legalcontent/EN/TXT/PDF/?uri=CELEX:52013SC0444\&from=EN Accessed on 10/04/2015

International Organization for Standardization (ISO) 2006a. Environmental management - Life cycle assessment - Principles and framework. ISO 14040:2006; Second Edition 2006-06, Geneva.

International Organization for Standardization (ISO) 2006b. Environmental management - Life cycle assessment - Requirements and guidelines. ISO 14044:2006; First edition 2006-07-01, Geneva.

International Organization for Standardization (ISO) LCA methodology: http://www.ecoinvent.org/fileadmin/documents/en/Data_Quality_Guidelines/01_DataQualityGui deline_v3_Final.pdf. 
Larsen, A.W., Merrild, H., Moller, J., Christensen, T.H., 2012. Waste collection systems for recyclables: an environmental and economic assessment for the municipality of Aarhus (Denmark). Resour. Conserv. Recy. 30, 744-754.

Laurent, A., Bakas, I., Clavreul, J., Bernstad, A., Niero, M., Gentil, E., Huschild, M.Z., Christensen, T.H., 2014. Review of LCA studies of solid waste management systems - Part I: Lessons learned and perspectives. Waste Manage. 34, 573-588.

Lilja, R., 2009. From waste prevention to promotion of material efficiency: change of discourse in the waste policy of Finland. J. Clean. Prod. 17, 129-136.

Massarutto, A., de Carli, A., Graffi, M., 2011. Material and energy recovery in integrated waste management systems: A life-cycle costing approach. Waste Manage. 31, 2102-2111.

Menikpura, S.N.M., Sang-Arun, J., Bengtsson, M., 2013. Integrated Solid Waste Management: an approach for enhancing climate co-benefits through resource recovery. J. Clean. Prod. 58, 34-42.

Milutinovic, B., Stefanovic, G., Dassisti, M., Danijel, M., Vuckovic, G., 2014. Multi-criteria analysis as a tool for sustainability assessment of a waste management model. Energy J. 74, 190-201.

OECD, 2013. Environment at a Glance: OECD Environmental Indicators, OECD Publishing, Paris

Plasticker website:http://plasticker.de/preise/marktbericht2 en.php?j=12\&mt=9\&quelle=bvse

Plastic europe's eco-profiles: http://www.plasticseurope.org/documents/document/20110421141821plasticseurope eco-profile methodology version2-0_2011-04.pdf. Accessed on 10/04/2015

Plastics Europe, 2011, Plastics - The Facts 2011: An Analysis of European Plastics Production Demand and Recovery for 2010.

Plastics Europe's eco-profiles: http://www.plasticseurope.org/plasticssustainability/eco-profiles.aspx

Reich, M.C., 2013. An Economic assessment of municipal waste management systems - case studies using a combination of life cycle assessment (LCA) and life cycle costing (LCC). J. Clean. Prod. $13,253-263$.

Resource Efficiency Roadmap: http://ec.europa.eu/environment/resource efficiency/ Accessed on $10 / 04 / 2015$

Raw Materials Initiative: http://ec.europa.eu/enterprise/policies/raw-materials/index_en.htm

Simpson, D., 2012. Knowledge recourses as a mediator of the relationship between recycling pressures and environmental performance. J. Clean. Prod. 22, 32-41.

Song. Q., Wang, Z., Li, J., 2013. Environmental performance of municipal solid waste strategies based on LCA method: a case study of Macau. J. Clean. Prod. 57, 92-100.

Tabasova, A., Kropac, J., Kermes, V., Nemet, A., Stehlik, P., 2012. Waste-to-energy technologies: Impact on environment. Energy J. 44, 146-155.

Tan, S.T., Lee, C.T., Hashim, H., Ho, W.S., Lim, J.S., 2014. Optimal process network for municipal solid waste management in Iskandar Malaysia. J. Clean. Prod. 71, 48-58.

Thomas, B., McDougall, F., 2005. International expert group on life cycle assessment for integrated waste management. J. Clean. Prod. 13, 321-326. 
UNEP-SETAC Live Cycle Initiative: http://www.lifecycleinitiative.org/ Accessed on 10/04/2015

WRATE: http://www.wrate.co.uk/Page/Download Accessed on 10/04/2015

WRAP, 2008. Kerbside Recycling: Indicative Costs and Performance. The Old Academy, Oxon, p.33.

Available

at:

http://www.wrap.org.uk/sites/files/wrap/Kerbside\%20collection\%20report\%20160608.pdf Accessed on 10/04/2015 


\section{Supplementary material}

\section{Table S1}

Table S2

Table S3

Table S4 